\title{
REVIEW I The Cambridge Companion to The Rolling Stones
}

Victor Coehlo and John Covach (eds.)

Cambridge: Cambridge University Press, 2019

$9781107030268 / 9781107651111$ (HB/PB)

\section{Lee Marshall \\ University of Bristol \\ I.marshall@bristol.ac.uk}

The Rolling Stones are one of the most successful, long-lasting and influential popular music acts of all time. As such, it is perhaps surprising that academic accounts of them are so thin on the ground. Lacking the harmonic and melodic innovation of The Beatles, or the lyrical dexterity of Bob Dylan, they have yet to catch the eye of the musicologists and literary theorists whose collective efforts have resulted in groaning bookshelves throughout the land. Neither have they attracted those with a more cultural studies bent, perhaps warded off by an aversion to anything that smells of rockism and its awkward relationship to sexism, racism and other kinds of identity politics. The Stones, it seems, are immune to academic analysis (or academic analysts, perhaps, are immune to The Stones).

In this context, Victor Coelho and John Covach's collection, The Cambridge Companion to The Rolling Stones, is a very welcome addition to the select field of Rolling Stones studies. According to the preface, the book is 'intended to stimulate fresh thinking about the group... It further broadens the approach to their music by considering new issues about sound, culture, media representation, the influence of world music, fan communities, group personnel, and the importance of their revival, post-1989' (xix-Xx). The book is structured into three parts: 'Albums, Songs, Players, and the Core Repertory of the Rolling Stones'; 'Sound, Roots, and Brian Jones'; and 'Stones on Film, Revival, and Fans'. The ragtag nature of those titles reveals that the essays themselves are rather diverse, without any overarching theme or narrative. They range from an analysis of the band on film to a Deleuzian reading of Brian Jones as an 'assemblage'. The chapters I found most rewarding were: Paul Harris's discussion of The Stones' reception during in the 1970s, in which he argues

IASPM Journal vol.10 no.1 (2020) 
that the band were repeatedly expected to 'do something about the state of rock' (87, italics original); Daniel Beller-McKenna's account of the country influence in the band's output, which first emerges in 1968 and can be partly attributed to the varying influences of Ry Cooder and Gram Parsons; and Victor Coelho's discussion of the band's 'exilic' image in the early 1970s (an 'itinerant sense of being... derived from the migratory aspects of the blues' (59)), though his conclusion that 'by $1973 .$. their narrative of travel, distance, and plurality of voices [had] singularized into language of the city' (71) is sadly undeveloped.

Despite the virtues of the individual essays, however, the collection as a whole suffers from a narrowness of scope that limits its contribution to the field. Like many works on similar artists, the majority of its analysis is chained to the long 1960s, particularly the group's heyday of 1968-1972. The aforementioned chapter by Harris is the one substantive chapter that focuses on their post-Exile On Main Street career, and this primarily discusses the reception to 1978's Some Girls album. Similarly, the discussion in the 'The Rolling Stones on Film' overwhelmingly concentrates on material before 1973 - the author offers a tantalising nugget in highlighting how the band have increasingly taken control of their own video footage in order to present their desired image (181), but does not discuss what exactly they want that image to be and how they achieve it. Meanwhile, the chapter called 'Second Life and the Dynamics of Revival: The Stones after 1989' is a desultory nine pages long. While it is beyond dispute that the band's most creative and socially significant years were during their first decade, the lack of serious analysis beyond that does their later career an injustice and misses out many of the things that make the band so interesting.

This narrowness of scope perhaps reflects a certain disciplinary narrowness among its contributors. Despite a claim to be 'de-siloing' the field (xix), its contributors are mostly (ethno)musicologists from North America, complemented by a film studies scholar, a filmmaker and a musician. The end result is that there is precious little on the social and cultural significance of the band, and nothing on their business practices. Yet, arguably, it is in these areas that the band has been most influential, helping construct the business of rock music, pushing the boundaries on things like branding and concert staging - and it is in these fields that they continue to be ground-breaking (in the development of new ticket-pricing strategies, for example). I appreciate that not everyone wants to pick up a book about The Rolling Stones to read about ticket-pricing strategies, but perhaps the most interesting thing about the band is their continual intertwining of art and commerce, reconciling (some might say steamrollering) the apparent contradiction between authenticity and 'selling out'. To ignore these issues is to ignore an important part of what makes The Stones distinctive. Yet while there is a chapter devoted to the musicians who have significantly contributed to The Stones' sound, such as Nicky Hopkins and Bobby Keys, there is barely a mention of business figures like Andrew Oldham, Allan Klein and Michael Cohl who have played similarly important roles in shaping the band's image and career. Neither is there any discussion of other crucial issues such as the band's complicated relationships to racial politics and sexual identity, or what their longevity can tell us about issues related to youth and ageing. It is not, simply, only rock and roll.

Overall, it is not entirely clear what purpose the collection serves. It is not exhaustive enough to be a genuine 'companion' to those (students?) new to the band, and the esoteric nature of some of the chapters imply it is intended to be more than a mere primer. However, in many cases neither does it seem that the chapters come from people with specific expertise or interest in the band but, rather, from scholars with other expertise 'trying their hand' at The Stones. The end 
result is that the book feels distant from its subject - the only time I got a sense of the band's vitality, of what it is like to be excited by the band, is in Philippe Puicouyoul's wonderful account of trying to squeeze his way to the front of the crowd at Hyde Park in 1969.

So, to reiterate what I wrote at the beginning, this collection is a welcome step in addressing the scarcity of academic analysis of The Rolling Stones. However, many more books need to be written in order to capture some of the complexity (and longevity) of the subject. 